\title{
IDV MODEL FOR SUSPENDED SAND TRANSPORT UNDER WAVES IN RIPPLE REGIME
}

\author{
DANG HUU CHUNG \\ Institute of Mechanics, NCST of Vietnam
}

\begin{abstract}
In this paper the results of theoretical studies on suspended sand transport under irregular waves in the ripple regime are presented. The results from the IDV model, which simulates the instantaneous velocity and sand concentration from close to the bed up to higher in the water column are obtained. The model is based on the classical diffusion approach taking both the turbulence-related and the effective waverelated diffusion into account. It shows that the time-averaged sand concentrations can be simulated reasonably well in the ripple regime using calibrated equations. Especially, the proposed formula for the diffusion coefficient by wave, considerably improved the behaviour of vertical distribution of suspended sediment concentration. Finally, the waverelated suspended sediment transport in depth-integration is computed and compared with the measured data. The accuracy of the suspended transport was found to be strongly dependent on using measured data or predictive formula for concentration at the bed boundary.
\end{abstract}

\section{Introduction}

The phenomenon of sediment transport is a complicated natural process and so far it has not been comprehensively understood. This problem attracts attentions of many researchers with different solutions of both mathematical and physical models to achieve a better understanding of this process. The suspended. sand transport rate in the coastal zone comprises two major components: the current-related transport component and the wave-related one. The current-related transport component is considered to be the convective sand transport carried by the mean currents such as tide, wind and wave-driven currents in the presence of short (high-frequency) surface waves acting as stirring agents. The wave-related sand transport is herein defined as the transport of sand particles by the oscillating (orbital) fluid motion due to high-frequency waves. The current-related transport over rippled beds has been studied in considerable detail (Van Rijn et al., 1993; Van Rijn and Havinga, 1995), but the wave-related transport is less well known. Both the magnitude and direction of the wave-related transport vary depending on the precise geometry of the ripples: relatively flat ripples may result in onshore- directed transport, whereas steep vortex-induced ripples may yield offshore-directed 
transport due to phase differences between instantaneous fluid velocities and sand concentrations near the ripples (Vincent and Green, 1990; Osborne and Greenwood, 1992; Osborne and Vincent, 1996; Grasmeijer and Van Rijn, 1999, Van Rijn, 1993 and Van Rijn, 1998). Wave-related transport over a flat bed has been studied in more detail, based on numerous experiments in wave tunnels (see for overview: Ribberink, 1998). Generally, the wave-related transport over a flat bed is found to be onshore-directed for sand sizes larger than about $0.15 \mathrm{~mm}$, because phase differences are less important in the thin sheet flow layer.

This paper focuses on evaluating suspended sediment transport under irregular waves on the basis of a 1DV model, taking the influence of waves on the total diffusion and a ripple bed into account. The model is a modified version of the 1DV model of Ribberink and Al Salem $(1991,1995)$ by expending computation for irregular waves in the ripple regime. The results will be used to show whether a diffusion-type model can be applied to simulate the suspension mechanism by ripple-induced vortices. The vortex-induced transport process may well be a convective process related to the migrational behaviour of oscillating coherent ripple-induced vortices rather than a turbulence-induced diffusion process as pointed out by Nielsen (1992).

\section{Mathematical model for instantaneous velocities and sand con- centrations}

A 1DV point model based on a numerical solution of the time-dependent sediment diffusion equation, has been used to simulate the instantaneous sand concentrations. The model is a modified version (including irregular waves and vortex-related mixing) of the model explained by Ribberink and Al-Salem (1991 and 1995). Other researchers such as Jonsson (1963); Kajiura (1968), Horikawa and Watanabe (1968), Bakker (1974), Brevik (1981), Fredsoe et al. (1985) and Rakha et al. (1997) have used similar models. Most often these models have been used for plane bed conditions, but Rakha et al. (1997) applied their model to compute the profile evolution in the surf zone with ripples along a considerable portion of the profile.

The turbulent fluid movement for (horizontal) uniform flow in the vertical plane is considered, assuming that the vertical velocity is relatively small compared with the horizontal velocity. Furthermore, it is assumed that the region of flow can be divided in two layers, in which the upper layer has no vertical velocity gradient. Hence, by using the term of pressure gradient from the equation for the upper layer, the movement in the lower layer is described by the Reynolds' equation as follows: 


$$
\frac{\partial u}{\partial t}=\frac{\partial u_{0}}{\partial t}+\frac{\partial}{\partial z}\left(\nu_{t} \frac{\partial u}{\partial z}\right), \quad z_{0} \leq z \leq h
$$

in which $u(z, t)$ is the horizontal velocity in the oscillatory lower layer with the depth $h, u_{0}$-the horizontal velocity at elevation $z=h$ distinguishing between the lower and the upper layer, $t$-time, $z$-elevation above bed, $\nu_{t}$-turbulent viscosity and $z_{0}$-position of zero velocity.

Eq.(2.1) is suitable to simulate the orbital flow field over a plane bed or a bed with relatively flat ripples (no flow separation). It can not simulate the detailed vortex motions over pronounced ripples, which basically is a horizontal non-uniform process. Since the attention is focussed on the wave-related suspended transport, eq.(2.1) is herein used to describe the general orbital motion and the turbulence-related mixing characteristics. The basic idea is to evaluate the performance of a relatively simple model with respect to the suspension characteristics over a rippled bed and to see whether the model can be adjusted to produce the proper wave-related transport rates or not.

In order to close the equation, Prandtl's theory on mixing length as turbulence closure is used and the eddy viscosity is described by

$$
\nu_{t}=\beta_{1} \ell^{2}\left|\frac{\partial u}{\partial z}\right|
$$

in which $\beta_{1}$ is the eddy viscosity adjusting coefficient (equal to 1 ), $\ell$ is the mixing length and determined by Prandtl's formula:

$$
l=\kappa z
$$

where $\kappa$ is the Von Karman constant $(\kappa=0.4)$.

The initial and boundary conditions used in the model are given in the following.

- The boundary conditions at $z=h$ and $z=0$ :

$$
\begin{aligned}
\left.u(z, t)\right|_{z=h} & =f_{1}(t) \\
\left.u(z, t)\right|_{z=z_{0}} & =0
\end{aligned}
$$

in which $f_{1}(t)$ is a given function from measurement (data record of irregular wave velocities);

- The initial condition:

$$
\left.u(z, t)\right|_{t=0}=f_{2}(z), \quad z_{0} \leq z \leq h
$$


in which $f_{2}(z)$ is given function of velocity. A hyperbolic tangent distribution is used for the initial velocity based on the initial value at $z=h$.

Using the same assumptions as for flow equation (2.1), the vertical distribution of sediment concentration is described by the 1DV diffusion equation as follows:

$$
\frac{\partial c}{\partial t}+\frac{\partial}{\partial z}\left(w-w_{s}\right) c=\frac{\partial}{\partial z}\left(\varepsilon_{s} \frac{\partial c}{\partial z}\right), \quad z_{a} \leq z \leq h
$$

in which: $w$ is the vertical velocity of flow, $w_{s}$ the constant settling velocity of sediment particle, $c$ the volume concentration, $z_{a}$ the reference level, and $\varepsilon_{s}$ the diffusion coefficient for sediment.

To represent additional vortex-related suspension processes, the overall sediment mixing coefficient was modelled as the sum of the ones by bottom-induced turbulence and effective vortex-induced mixing:

$$
\varepsilon_{s}=\sqrt{\varepsilon_{s t}^{2}+\varepsilon_{s w}^{2}}
$$

in which $\varepsilon_{s t}, \varepsilon_{s w}$ are the mixing coefficients for sediment due to turbulence and due to vortex motions, respectively. The turbulence-related sediment mixing coefficient is related to the eddy viscosity $\nu_{t}$ by a coefficient $\beta_{2}$ (assumed to be equal to 1 ):

$$
\varepsilon_{s t}=\beta_{2} \nu_{t}
$$

The vortex-induced mixing is supposed to be described by the following formula:

$$
\varepsilon_{s w}=\frac{1}{n} \hat{U} z\left(1-\frac{z}{h}\right)
$$

Eq. (2.10) is based on dimensional analysis and assumes that the sand concentration profile is of the hyperbolic type, $c \sim(h / z-1)^{n}$, with $n$ being a calibration coefficient most likely depending on grain size and ripple dimensions. Furthermore, it is assumed that peak orbital velocities, $\hat{U}$, are dominant in driving the vortices. The peak orbital velocity is described as:

$$
\hat{U}=\left.\frac{1}{2}\left(U_{o n}(z, T)+U_{o f f}(z, T)\right)\right|_{z=h}
$$

in which $U_{\text {on }}, U_{\text {off }}$ are onshore and offshore amplitudes of peak orbital velocity in case of irregular waves, respectively; $T$ is the wave period. The effective vortex-induced mixing has been determined by calibration using the measured time-averaged saind concentrations.

The boundary equations for the sediment diffusion equation are: 
- The initial condition:

$$
\left.c(z, t)\right|_{t=0}=f_{3}(z), \quad z_{a} \leq z \leq h
$$

in which $f_{3}(z)$ is a given function from measured data.

- The boundary condition at $z=h$ :

$$
\varepsilon_{s} \frac{\partial c}{\partial z}=-w_{s} c, \quad z=h
$$

- The boundary condition at $z=z_{a}$ :

$$
\left.c(z, t)\right|_{z=z_{a}}=c_{a}(t), \quad \text { at } \quad z=z_{a}
$$

or

$$
\varepsilon_{s} \frac{\partial c}{\partial z}=-w_{s} c_{a}, \quad \text { at } \quad z=z_{a}
$$

in which $c_{a}$ is a given formula or a measured time series.

The applied expression reads as:

$$
c_{a}=m \rho_{s} \frac{\left(\theta^{\prime}-\theta_{c r}^{\prime}\right)^{1.5}}{D^{*}}
$$

in which $\theta^{\prime}$ is instantaneous dimensionless bed shear stress related to the grains; $\theta_{c r}^{\prime}$ critical dimensionless bed shear stress known as Shields parameter; $\rho_{s}$ density of sediment; $D^{*}$ dimensionless particle diameter; and $m$ is an empirical coefficient (calibration) related to ripple characteristics $r, \lambda$, being ripple height and length respectively. The reference level is assumed to be equal to the effective bed roughness $k_{s}$, which is taken as equal to the ripple height.

\section{Calibration of the model and numerical solutions}

The finite difference method based on the implicit scheme of Crank-Nicolson was used to solve equations (2.1), (2.4)-(2.6) for horizontal velocity and the implicit upwind scheme was used in equations (2.7), (2.12)-(2.14) for vertical distribution of sediment concentration. It should be noted that the grids for flow and sediment diffusion equations are different and that a staggered grid has been used for more accurate and stable computation results. The data sets are given in Table 1 and basic input values of the model are given in Table 2: $D_{50}$ of the bed, $w_{s}=$ constant, fall velocity of suspended sand (based on settling tests using suspended samples) and effective bed roughness $k_{s}$, which is taken as equal to the measured ripple height. 
First, the calibration of the vortex-related mixing coefficient is considered by fitting measured and computed time-averaged sand concentrations. It is shown in Fig. 1 that the time-averaged sand concentration is much too small when only the turbulence-related mixing coefficient is used. Introducing a vortex-related mixing coefficient as determined by eq. (2.10), improved the vertical distribution of sediment concentration considerably, compared with the measurement results. Similar results were obtained for all other tests. Under the action of bottom-induced turbulent mixing the suspended sediment concentration mainly assembles near the bed and decreases quickly in the upward direction. The 24 available test results (Dang Huu,C. and Grasmeijer,B.T.,1999) of time-averaged sand concentrations have been used to determine the $n$-coefficient of the vortex-related mixing coefficient and the $m$-coefficient of the reference concentration expression by fitting the measured and computed time-averaged concentrations. The results are given in Table 2.

The $n$-coefficient was found to depend on the grain size of the bed material: $n=12$ for coarse sand of $0.33 \mathrm{~mm}$ and $n=38$ for finer sand of $0.16 \mathrm{~mm}$. A smaller $n$-value implies a stronger vortex-related mixing, which seems realistic because the ripples were most pronounced (steep vortex ripples with $r / \lambda=0.27$ ) in the tests with a coarse sand bed of $0.33 \mathrm{~mm}$.

The $m$-coefficient was found to be related to the ripple steepness $(r / \lambda)$ with $m$-values in the range of $m=0.04$ for $r / \lambda=0.042$ to $m=0.27$ for $r / \lambda=0.5$. The results can be represented by

Table 1. Measurement programme

\begin{tabular}{clcccc}
\hline $\begin{array}{c}\text { Data } \\
\text { set }\end{array}$ & $\begin{array}{l}\text { Measurement } \\
\text { No. }\end{array}$ & $\begin{array}{c}\text { Number } \\
\text { of test }\end{array}$ & $\begin{array}{c}\text { Grain } \\
\text { size } D_{50} \\
(\mathrm{~mm})\end{array}$ & $\begin{array}{c}\text { Wave } \\
\text { height } \\
\text { Hs (m) }\end{array}$ & $\begin{array}{c}\text { Orientation } \\
\text { of ASTM } \\
\text { (degree) }\end{array}$ \\
\cline { 1 - 2 } & A1, A1B, A2A, & 8 & 0.33 & 1.00 & -90 \\
& D1, D2, D3, D4, D5 & & & & -120 \\
II & B1A, B2A, B1B, & 8 & 0.33 & 1.25 & -90 \\
& E1, E2, E3, E4, E5 & & & & -120 \\
III & G1, G2, G3, G4, & 7 & 0.16 & 1.00 & -120 \\
& J1, J2, J3 & & & & -90 \\
IV & H1, H2, H3, H4, H5, & 9 & 0.16 & 1.25 & -120 \\
& K1, K2, K3, K4 & & & & -90 \\
V & M1, M2, M4 & 3 & 0.16 & 1.50 & -90 \\
\hline
\end{tabular}


Table 2. Input parameters for computations

\begin{tabular}{|c|c|c|c|c|c|c|c|c|c|}
\hline Test & $\begin{array}{c}T_{\max } \\
(\mathrm{s})\end{array}$ & $\begin{array}{c}u_{a}(z=h) \\
\left(m s^{-1}\right)\end{array}$ & $\begin{array}{l}w_{s} \\
(m)\end{array}$ & $\begin{array}{c}k_{3} \\
(m)\end{array}$ & $\begin{array}{c}z_{a} \\
(m)\end{array}$ & $\begin{array}{l}m \\
(-)\end{array}$ & $\begin{array}{l}n \\
(-)\end{array}$ & $\begin{array}{c}r \\
(m)\end{array}$ & $\begin{array}{c}\lambda \\
(m)\end{array}$ \\
\hline A1 & 892.0 & -0.03102 & 0.03 & 0.06 & 0.06 & 0.5 & 12.0 & 0.06 & 0.22 \\
\hline D1 & 897.0 & -0.00493 & 0.03 & 0.06 & 0.06 & 0.5 & 12.0 & 0.06 & 0.22 \\
\hline D3 & 888.5 & -0.00526 & 0.03 & 0.06 & 0.06 & 0.5 & 12.0 & 0.06 & 0.22 \\
\hline B1A & 890.5 & -0.03354 & 0.03 & 0.05 & 0.05 & 0.3 & 12.0 & 0.05 & 0.23 \\
\hline $\mathrm{B} 2 \mathrm{~A}$ & 893.5 & -0.03429 & 0.03 & 0.05 & 0.05 & 0.3 & 12.0 & 0.05 & 0.23 \\
\hline $\mathrm{B} 1 \mathrm{~B}$ & 117.5 & -0.03618 & 0.03 & 0.05 & 0.05 & 0.3 & 12.0 & 0.05 & 0.23 \\
\hline E3 & 894.5 & -0.01776 & 0.03 & 0.05 & 0.05 & 0.3 & 12.0 & 0.05 & 0.23 \\
\hline E4 & 652.5 & -0.01035 & 0.03 & 0.05 & 0.05 & 0.3 & 12.0 & 0.05 & 0.23 \\
\hline E5 & 896.5 & -0.00950 & 0.03 & 0.05 & 0.05 & 0.3 & 12.0 & 0.05 & 0.23 \\
\hline G1 & 892.0 & -0.03821 & 0.011 & 0.03 & 0.03 & 0.05 & 38.0 & 0.03 & 0.72 \\
\hline G2 & 894.5 & -0.01750 & 0.011 & 0.03 & 0.03 & 0.05 & 38.0 & 0.03 & 0.72 \\
\hline G4 & 892.5 & -0.02189 & 0.011 & 0.02 & 0.03 & 0.05 & 38.0 & 0.03 & 0.72 \\
\hline $\mathrm{J} 1$ & 897.0 & -0.03113 & 0.011 & 0.03 & 0.03 & 0.05 & 38.0 & 0.03 & 0.72 \\
\hline $\mathrm{J}_{2}$ & 895.5 & -0.03237 & 0.011 & 0.03 & 0.03 & 0.05 & 38.0 & 0.03 & 0.72 \\
\hline J3 & 356.0 & -0.03065 & 0.011 & 0.03 & 0.03 & 0.05 & 38.0 & 0.03 & 0.72 \\
\hline $\mathrm{H} 2$ & 823.5 & -0.03826 & 0.011 & 0.03 & 0.03 & 0.05 & 38.0 & 0.03 & 0.72 \\
\hline H3 & 898.5 & -0.03666 & 0.011 & 0.03 & 0.03 & 0.05 & 38.0 & 0.03 & 0.72 \\
\hline $\mathrm{H} 4$ & 894.5 & -0.02584 & 0.011 & 0.03 & 0.03 & 0.05 & 38.0 & 0.03 & 0.72 \\
\hline $\mathrm{H} 5$ & 893.0 & -0.03370 & 0.011 & 0.03 & 0.03 & 0.05 & 38.0 & 0.03 & 0.72 \\
\hline $\mathrm{K} 2$ & 898.5 & -0.02989 & 0.011 & 0.03 & 0.03 & 0.05 & 38.0 & 0.03 & 0.72 \\
\hline K4 & 892.5 & -0.03552 & 0.011 & 0.03 & 0.03 & 0.05 & 38.0 & 0.03 & 0.72 \\
\hline M1 & 891.5 & -0.04407 & 0.011 & 0.02 & 0.02 & 0.05 & 38.0 & 0.02 & 0.72 \\
\hline M2 & 836.5 & -0.03225 & 0.011 & 0.02 & 0.02 & 0.05 & 38.0 & 0.02 & 0.72 \\
\hline M4 & 474.5 & -0.03092 & 0.011 & 0.02 & 0.02 & 0.05 & 38.0 & 0.02 & 0.72 \\
\hline
\end{tabular}

The measured velocities at $z=1.075 \mathrm{~m}$ are used as the upper boundary condition of the model and the sand concentrations at the lower boundary condition of $z=z_{a}=0.075 \mathrm{~m}$ are taken from measured concentrations as well as from equation (2.16). Based on these conditions, the model computations show quite 
good results for concentration at the lower elevations and for orbital velocity at. the higher elevations (close to the boundaries). Further away from the boundaries the discrepancy between computed and measured values gradually increases. It also shows that the computed instantaneous results based on the measured reference concentration are much better than those from equation (2.16). Furthermore, the computed instantaneous concentration shows less strong oscillation than the measured concentration. This latter effect results in less accurate predictions of the wave-related sediment transport rate, as will be shown later. The vertical distribution of the time-averaged sand concentrations is not much affected by the type of boundary condition (measured data or equation (2.16)), as shown in Fig. 2 . For all the cases under consideration the computed instantaneous velocities outside the layer affected by the ripples (roughly two ripple heights above the mean bed; $z>0.1$ to $0.2 \mathrm{~m}$ ) behave quite well in comparison with the measured velocities. The vertical distribution of the time-averaged velocities are shown in Figure 2. Considerable errors occur close to the bed in the vicinity of the ripples $(z<0.1 \mathrm{~m})$.

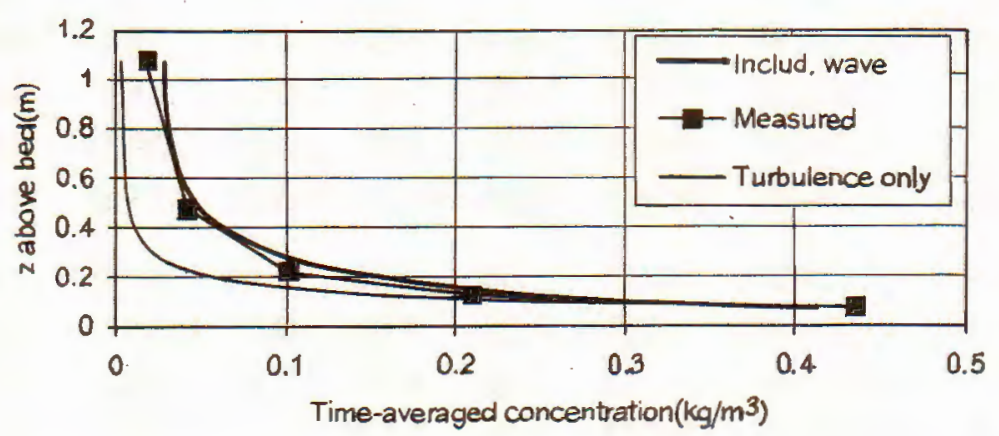

Fig. 1. Time-averaged concentration profile with and without wave-related diffusion (test G1)

Figure 3 shows computed and measured time-averaged velocity profiles for all 24 tests, in terms of mean values (and standard error range) for each of the 5 data sets. Figure 4 shows similar results for the time-averaged sand concentrations. The time-averaged sand concentrations at the higher elevations $(z>0.5 \mathrm{~m})$ are largest for data set $\mathrm{V}$, with the largest significant wave height and the finer sand of $0.16 \mathrm{~mm}$; whereas the near-bed concentrations are largest for the case with steep vortex ripples (data set I and II). These results show that a diffusion type model is quite good in simulating the time-averaged sand concentration distribution, provided that the vortex-related suspension mechanism is modelled by an effective mixing coefficient. The discrepancies of time-averaged concentration between using formula (2.16) and measured data for reference concentration are quite small. 
With regards to the standard errors of both the computed and measured resuits, it shows that the velocities change significantly for each test due to the presence of the ripples, while the standard errors for concentration are more stable at the same levels.
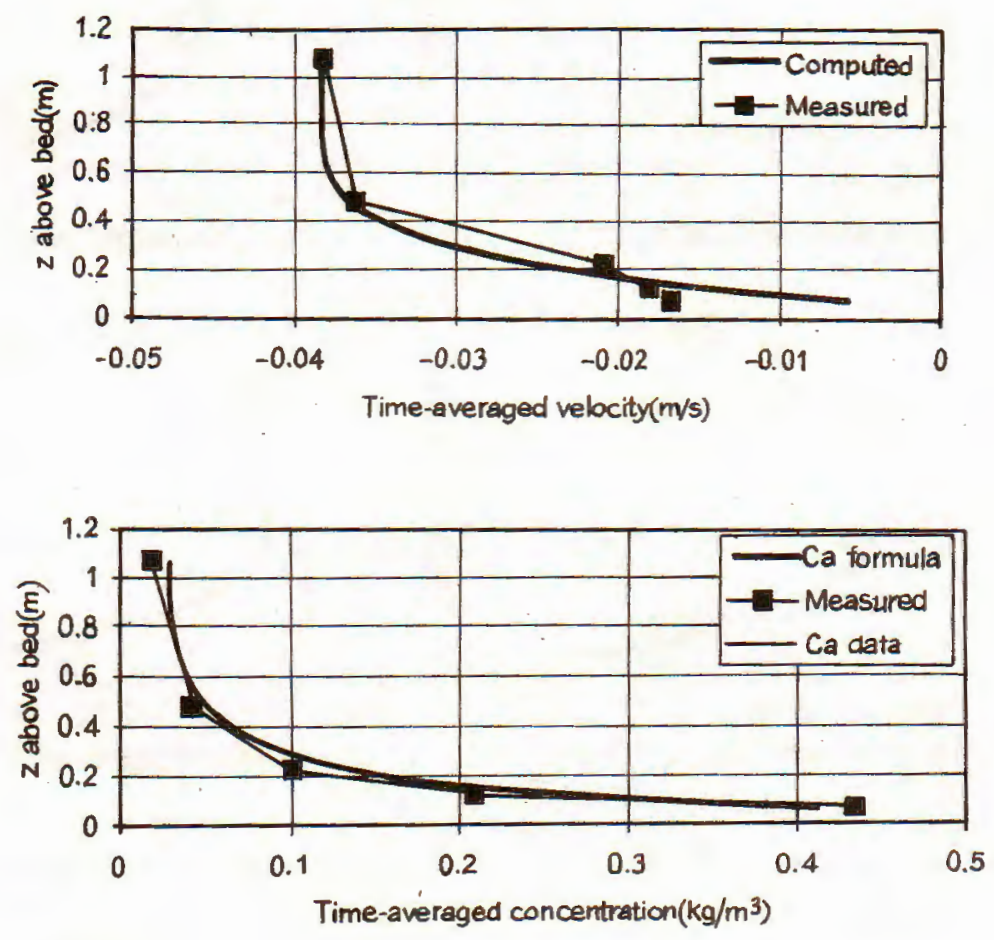

Fig. 2. Computed and measured time-averaged velocity and concentration profiles for test $\mathrm{G} 1$

\section{Evaluation of wave-related suspended transport rates}

The velocity and concentration computed by the model are the instantaneous quantities and they are represented as the sum of time-averaged component and the wave-related oscillations:

$$
\begin{aligned}
& u(z, t)=\bar{u}(z)+\widetilde{U}(z, t) \\
& c(z, t)=\bar{c}(z)+\widetilde{C}(z, t)
\end{aligned}
$$

The components due to high and low frequencies are not presented separately here. Therefore, the wave-related suspended sediment transport rate is defined as follows:

$$
Q_{w} \equiv \overline{(u-\bar{u})(c-\bar{c})}=\overline{u c}-\bar{u} \bar{c}
$$



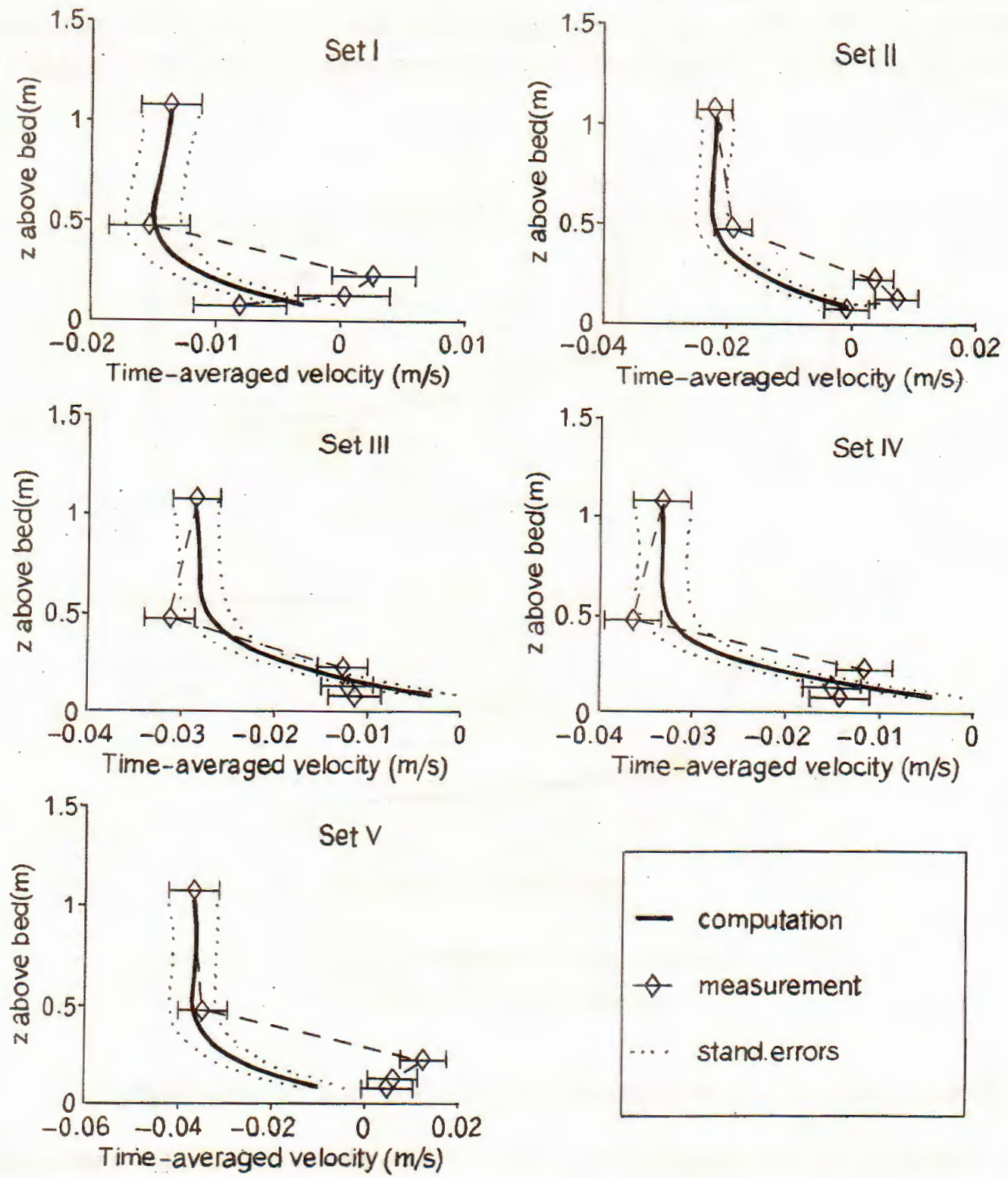

Fig. 3. Time-averaged velocities for combined tests

Expression (4.3) is applied to each computation result corresponding to the tests in Table 2. Through comparison with the data, it shows that the model results in simulating the wave-related transport close to the bed are not accurate if the reference concentration is computed by a bed-shear stress related expression. The model results are considerably better if the measured sand concentrations of the lowest point are used as boundary condition for the fine sand bed of $0.16 \mathrm{~mm}$. This can also be observed from Fig. 5, which presents computed depth-integrated 

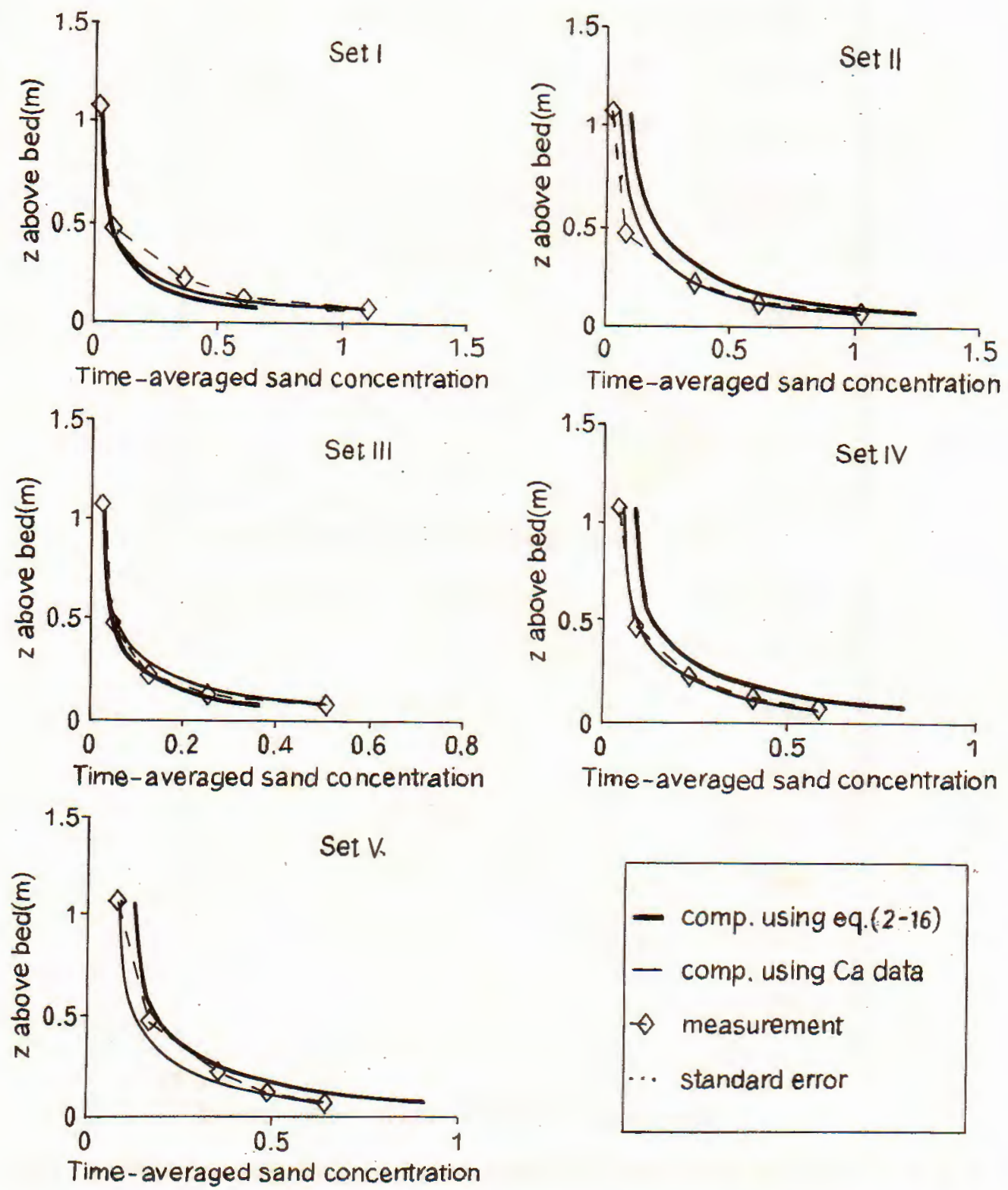

Fig. 4. Time-averaged sand concentrations for combined tests

transport rates (between the lowest $z=0.075 \mathrm{~m}$ and the highest measurement point $z=1.075 \mathrm{~m}$ ) versus measured depth-integrated transport rates (between the same points). The dashed lines are absolute error boundaries with values of $\pm 0.01 \mathrm{kgm}^{-1} \mathrm{~s}^{-1}$.

There is a range of causes for the discrepancies between measured and computed wave-related suspended transport rates. As seen from the obtained results, 

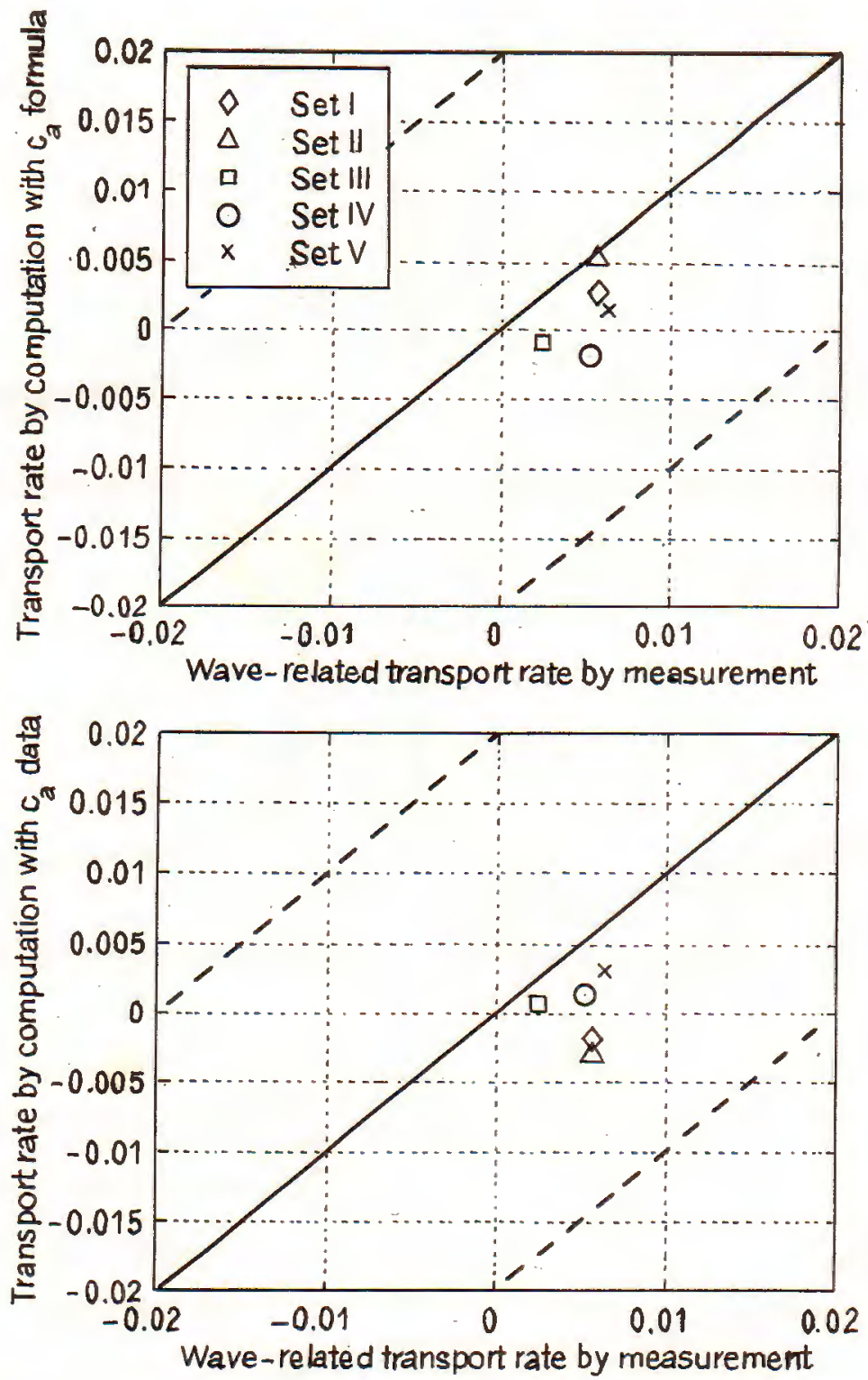

Fig. 5. Computed versus measured (depth-integrated) wave-related transport rates

the computed instantaneous concentrations do not agree well with the measured values although the time-averaged values are quite good. This problem is related to the geometry of the ripples as well as to the dynamics of entrainment and transportation of sediment particles from the rippled bed into the flow. It appears that the instantaneous behaviour of the vortices and associated sand concentrations may not be represented sufficiently accurately by the classical diffusion type model. Moreover, the interaction between sediment and fluid particles is not considered in the present model. The changes of fluid density and turbulence due to the presence of high near-bed sand concentrations may influence the dynamics process of flow and sediment. 


\section{Discussion and conclusions}

The ripple steepness is a very important factor, because it decides the scale of bed roughness (see Hitching and Lewis, 1999) and hence, has a strong influence on vertical distribution of horizontal flow velocity and sand concentration. As the precise measurement location with respect to the ripple crest is unknown for these Delta flume experiments, many repetitive measurements have been made to ensure representative sampling at various locations along the migrating ripples. Thus, the measured mean profiles of Fig. 3 represent some discrepancies of a spatiallyaveraged (over a ripple length) mean velocity profile. The error ranges give an indication of the horizontal variability involved. Comparison of measured and computed fluid velocities for the $0.33 \mathrm{~mm}$ sand (Fig. 3) shows that a simple 1DVmodel can not be used to determine accurate values of the mean currents very close to steep ripples. Somewhat better results are obtained for data sets II and IV of the $0.16 \mathrm{~mm}$ sand bed with flat ripples using an effective bed roughness equal to the ripple height. Accurate simulation of the flow field near a rippled bed basically requires the application of a $2 \mathrm{DV}$ model in combination with a higher order turbulence closure ( $K-\varepsilon$ method) or direct large-scale eddy simulation (LES method), which is beyond the scope of the present study.

The time-averaged sand concentrations can be reasonably well simulated for both sand sizes using the classical diffusion approach, provided that the reference concentration near the bed is modelled with sufficient accuracy and that the vortex-related mixing characteristics are taken into account (calibration). Neglecting the vortex-related mixing coefficient, yields time-averaged sand concentrations that are much too small (Fig. 1). Further research is necessary to relate the reference concentration and the vortex-related mixing coefficient to relevant hydrodynamic, sediment and bed form parameters. The effect of the ripple geometry has to be included to represent all sand concentration peaks near the bed. The computed instantaneous sand concentrations at various elevations away from the bed, show better agreement when measured data are used as a bed boundary condition. For all cases, the computed instantaneous sand concentrations show less strong oscillations than the measured data, which is an indication that the diffusion approach is not fully capable of simulating the instantaneous processes. However, this does not seem to affect the accuracy of the time-averaged sand concentrations and hence, the current-related transport very much, but it is of major importance for the wave-related suspended transport processes. This latter process can not be simulated very accurately by the present $1 D V$ model in the case of a rippled bed, especially when the reference concentration is not accurately modelled.

For all cases the measured wave-related suspended transport rates due to the high frequency waves are directed onshore, whereas the current-related suspended transport rates are directed offshore. The transport rates due to low frequency are of minor importance and have a tendency for offshore direction similar to 
time-averaged transport components.

The results of the present study. for sand transport under irregular waves over a bed of $0.16 \mathrm{~mm}$ sand and $0.33 \mathrm{~mm}$ sand can be summarized by the following conclusions:

- The ripple geometry is strongly affected by the bed material characteristics: steep vortex ripples with $r / \lambda=0.22$ to 0.27 for the $0.33 \mathrm{~mm}$ sand (data sets I and II, see Table 1) and relatively flat ripples with $r / \lambda=0.04$ for $0.16 \mathrm{~mm}$ sand (data sets III, IV and V);

- The suspended sediment transport mainly occurs in the near-bed layer with a thickness of about 0.3 to $0.5 \mathrm{~m}$ (water depth of $4.55 \mathrm{~m}$ ), which is roughly equivalent to 10 to 20 times the ripple height;

- The measured wave-related suspended transport due to the high frequency waves is directed onshore, whereas the current-related suspended transport is directed offshore; the transport rates due to low frequency are of minor importance and have a tendency for offshore direction, similar to time-averaged transport components;

- The onshore-directed wave-related suspended transport increases with significant wave height (between 1 and $1.5 \mathrm{~m}$ ) and decreases with sand size; the latter effect is related to the effect of decreasing ripple steepness and hence, less strong vortex motions for decreasing sand size;

- The instantaneous velocities and sand concentrations should be measured in points down to $z=0.01 \mathrm{~m}$ above the bed to determine accurate values of the depth-integrated high-frequency transport rate;

- The 1DV model based on the classical diffusion approach shows a good ability to simulate the time-averaged suspended sand concentrations and hence the current-related suspended transport in the ripple regime, provided that the reference concentration near the bed and the vortex-related mixing are represented with sufficient accuracy; both parameters are strongly related to the ripple characteristics.

\section{Acknowledgements}

This publication is completed with financial support from the National Basic Research Program in Natural Sciences and from Utrecht University (Netherlands).

The experiments were done in the Delta flume of Delft Hydraulics under the framework of the LIP-program of the European Commission.

The author would like to express his gratitude to Prof.Leo C. Van Rijn for his very sincere help and to the University of Utrecht for providing the scholarship to carry out the present research. The SEDMOC project, sponsored (under contract MAS-3-CT97-0015) by the European Commission Directorate General XII for Science, Research and Development is gratefully acknowledged for providing funds to support the analysis of the data set. 


\section{REFERENCES}

1. Bakker W. T. Sand concentration in oscillatory. Proc. $14^{\text {th }}$ ICCE, Copenhagen, ASCE, Vol. 2, 1974, pp. 1129-1148.

2. Brevik I. Oscillatory rough turbulent boundary layers. ASCE WW3, No. 107, 1981, pp. 175-188.

3. Dang Huu Ch. and Grasmeijer B. T. Analysis of sand transport under regular and irregular waves in large-scale wave flume. Report R99-05, IMAU, Utrecht University, The Netherlands, 1999.

4. Dang Huu C., Leo C. Van Rijn and Grasmeijer B. T. Wave-related suspended sand transport under irregular waves in the ripple regime. Coastal Engineering (submitted)

5. Fredsoe J., Andersen O. H. and Silberg S. Distribution of suspended sediment in large waves. Journal of Waterway, Port, Coastal and Ocean Engineering, Vol. 111, No 6, 1985, pp. 1041-1059.

6. Grasmeijer B. and Van Rijn L. C. Transport of fine sands by currents and waves III: Breaking waves over barred profile with ripples. Journal of Waterway, Port, Coastal and Ocean Engineering, Vol. 125, No 2, 1999, pp. 71-79.

7. Hitching E. and Lewis A. W. Bed roughness over vortex ripples. Proc. $4^{\text {th }}$ Int. Symp. on Coastal Engineering and Coastal Sediment Processes, Long Island, New York, June 21-23, 1999, ASCE, Vol. 1, 1999, pp. 18-30.

8. Horikawa K., Watanabe A. Laboratory study on oscillatory boundary layer flow. Proc. 11 ${ }^{\text {th }}$ Coastal Eng. Conf., 1968, pp. 467-486.

9. Jonsson I. G. Measurements in the turbulent wave boundary layer. Proc. $10^{\text {th }}$ Congress IAHR, 1963, pp. 85-92.

10. Kajiura K. A model of the bottom boundary layer in water waves. Bull. Earthquake Res. Inst, Vol.46, 1968, pp. 75-123.

11. Nietsen P. Coastal bottom boundary layers and sediment transport. World Scientific Publishing Corporation, New York, 1992.

12. Osborne P. D. and Greenwood B. G. Frequency-dependent cross-shore suspended sediment transport 2: A barred shoreface. Márine geology 106, 1992, pp. 25-51.

13. Osborne P. D. and Vincent C. E. Vertical and horizontal structure in suspended sand concentrations and wave-induced fluxes over bed forms. Marine Geology 131, 1996, pp. 195-208.

14. Rakha K. A., Deigaard R. and Brфker I. A Phase-resolving cross-shore sediment transport model for beach profile evolution. Coastal Eng. 31, 1997, pp. 231-261.

15. Ribberink J. S. Bed-load transport for steady flows and unsteady oscillatory flows. Coastal Engineering 34, 1998, pp. 59-82. 
16. Ribberink J. S. and Al-salem A. Near-bed sediment transport and suspended sediment concentrations under waves. Proc. Int. Symposium on: "The transport of suspended sediment and its mathematical modelling", Florence, 1991.

17. Ribberink J. S. and Al-salem A. Sheet flow and suspension of sand in oscillatory boundary layers. Coastal Engineering 25, 1995, pp.205-225.

18. Van Rijn L. C. Principles of sediment transport in rivers, estuaries and coastal seas, Aqua Publications, Amsterdam, The Netherlands, 1993, p. 730.

19. Van Rijn L. C. Principles of coastal morphology. Aqua Publications, Amsterdam, The Netherlands, 1998, p. 750.

20. Van Rijn L. C. et al. Transport of fine sands by currents and waves I. Journal of Waterway, Port, Coastal and ocean Engineering, Vol.119, No. 2, 1993,'pp. 123-143.

21. Van Rijn L. C. and Havinga F. J. Transport of fine sands by currents and waves II. Journal of Waterway, Port, Coastal and ocean Engineering, Vol. 121, No. 2, 1995, pp. 123-133.

Received December 15, 1999

\section{MÔ HİNH MỘT CHIỀU VẬN TẢI BÙN CÁT LƠ LỬNG DƯớI TÁC ĐộNG CƯA SÓNG TRONG ĐIÈU KIỆN ĐÁY GợN SÓNG}

Bài báo trình bày một vài kết quả nghiên cứu lý thuyết về vận tải bùn cát lơ lửng dưới tác động của sóng không đều trong điều kiện đáy gợn sóng. Từ mô hình một chiều, các giá trị tức thời về phân bố thẳng đứng của vận tốc và nồng độ được thu nhận. Mô hình dựa trên cơ sở khuyếch tán cổ điển có chú ý đến cá khuyếch tán rối và khuyếch tán do sóng. Kết quả cho thấy mô hình có khả năng mô phỏng tốt phân bố trung bình thời gian của nồng độ nhờ sử dụng các hệ số hiệu chỉnh. Đặc biệt, việc đưa vào công thức bán thực nghiệm của hệ số khuyếch tán do sóng đã cái thiện đáng kể dáng điệu phân bố của bùn cát. Cuối cùng, tốc độ tải lơ lửng do sóng đã được tính và so sánh với giá trị được đo. Kết quả cho thấy độ chính xác của tốc độ tải phụ thuộc rất nhiều vào việc sử dụng trực tiếp giả trị ở biên đáy đối với nồng độ hay sử dụng công thức dự báo.

Institute of Mechanics, 264 Doi Can, Hanoi, Vietnam

Fax: 84-4-8333039, Email: Dhchung@im01.ac.vn 